\title{
Fundamental Misclassification, Worse Media, and Failure to Communicate: How "Complementary Medicine" Was Incorrectly Linked to Early Death
}

\section{John Weeks}

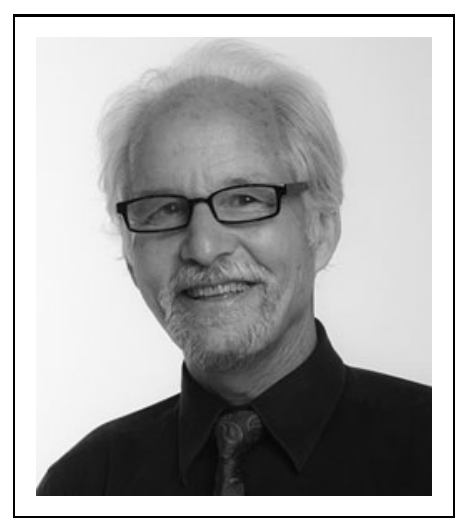

"A ROSE IS A ROSE is a rose is a rose." 1 American poet and author Gertrude Stein famously penned this line 105 years ago. The phrase is used to signify that things are what they are. By this same light, if cancer patients should choose to not listen to their oncologist and instead delay or disregard that advice, then the path they are choosing is an "alternative" to the recommendations of the conventional oncology provider. It is not a complement. When it comes to cancer care, alternative medicine is alternative medicine is alternative medicine.

A rose, to the authors of a recent widely reported article in JAMA Oncology, ${ }^{2}$ is apparently a begonia. The results caused the New York Times to warn readers, in a subheading, that "people who used herbs, acupuncture and other complementary treatments tended to die earlier than those who didn't." 3 At issue, as Society for Integrative Oncology (SIO) leaders have remarked in interviews following the wave of media, is a classic "misclassification error." As will be seen, the repeated confusion of "alternative" for "complementary" led to the faulty conclusion that complementary therapies kill. The authors state as much. When they removed those who denied or delayed treatment (a.k.a. chose "alternative" courses), the evidence of the association between "complementary therapy" use and diminished length of life "goes away."

In a separate study, the authors had already usefully found death rates higher among cancer patients who choose alternatives. ${ }^{5}$ Yet, with this follow-up examination, death associated with the choice of complementary treatments was unleashed into the public domain, corrupting the decision processes of untold multitudes who grope to find the best paths through a cancer diagnosis and treatment process. I interviewed and wrote on this topic elsewhere when the story and resulting media broke in July 2018. This column offers reflections on what was, at the very least, a disservice to the human beings and those who care for them when they are considering their plan after a cancer diagnosis, and what might be done.

\section{Misclassification Errors}

The misclassification by the Yale research team led by Skyler Johnson and James Yu was not merely to call alternative medicine users complementary medicine (CM) users. The misclassification was also on the other side of the ledger: the controls. Surveys have shown that $48 \%-88 \%$ of people with cancer try some complementary treatment. ${ }^{6}$ Johnson and $\mathrm{Yu}$ acknowledge this. They also note that most people do not communicate with their oncologists about their choices. These failures to communicate most certainly meant that a high percentage of those in the control group were using complementary therapies that were unreported.

On my request, JACM Statistics Editor Scott Mist examined the article. The apparent gravitas of the Johnson and $\mathrm{Yu}$ results comes with their sharing that their research was based on mining data on 1,901,815 patients in the U.S. National Cancer Registry. But they identified only 258 patients who met the study's criteria for "complementary medicine" use. How could this be? With the known high use of complementary practices, Mist concluded that "there should have been between 836,799 and 1,673,597 CM users. They found less than $0.01 \%$. That should have stopped the study right there. There is no way that less than $1 / 100$ th of the population is representative of the population of $\mathrm{CM}$ users." 4 To summarize: the most influential information in the findings of what Johnson and Yu classified as "complementary medicine" users were actually using these therapies as "alternative medicine." And logic dictates that a high percentage of the so-called controls were certainly CM users.

Editor-in-Chief, The Journal of Alternative and Complementary Medicine. 
To corrupt the metaphor a bit, neither the rose nor the begonia were what they were declared to be.

\section{Lack of Patient-Centered Cancer Care}

What lay behind these errors? A garbage-in-garbageout problem lets Johnson and Yu partially off the hook. They relied on a database that was neither built for, nor captured, the information they were evaluating. Two studies from researchers at the Mayo Clinic in the recent $J A C M$ Special Issue on Integrative Oncology underscore how poorly patient choices of complementary therapies are represented in doctor notes and electronic records. The titles alone capture the chasms: "Absent and Discordant Electronic Health Record Documentation of CAM in Cancer Care", and "Contending Worldviews in the Clinical Encounter: An Empirical Study of Complementary and Alternative Medicine Deliberations in Contemporary Medical Oncology.,"8

One wonders, do these dismal records of present oncologistpatient dialogue on complementary or alternative treatment suggest that most oncologists can distinguish between "complementary" and "alternative" and get it right in their notes? Not only were these oncologists not communicating with their patient about their extraclinical choices, when they were they could quite likely have been documenting the nuances between alternative and complementary wrong. The misclassification plaguing the Johnson and $\mathrm{Yu}$ article may have begun here, in the beginning, in the creation of suspect data on which the entire study and its conclusions rest.

\section{Lack of Interprofessional Collegiality}

Where the Yale team is not off the hook, especially in the emerging interprofessional era, is in their failure to respect the integrative oncology field enough to bring someone with expertise onto their team. Anyone with familiarity with the evolving field of integrative oncology would have immediately recognized the problems their method would encounter and then the problems in the article. Unfortunately, the Yale team did not deem it necessary to include an expert in the field they proceeded to publicly damn. Did the editors of JAMA Oncology seek out a peer with actual expertise before publishing a message they must have known would spread like wildfire in the media? SIO president Lynda Balneaves underscores the sad lack of collegiality: "Honestly, this has disappointed me. It's too bad that the authors didn't just connect with researchers knowledgeable in integrative oncology before doing this work. There are a lot of us out there." 9 The evidence of a burgeoning field with respect and endorsement in conventional oncology circles is readily at hand. ${ }^{10,11}$

\section{Call for Retraction?}

The decision to publish this research was a very big deal-a sort of life and death judgment on the field, especially with the way "complementary medicine" played in resulting headlines. Multiple individuals, institutions, and organizations - including the SIO_-sent critical letters to JAMA Oncology. ${ }^{4}$ As of this writing, none of their letters have been published. To my knowledge, none called for retraction. Balneaves believes that even the "major misclassification bias" does not hit the threshold to call for retraction. She strategically prefers that JAMA Oncology open a dialogue on integrative oncology that could prove broadly educational for the field. Yet the criticisms of the Johnson and Yu study sound multiple notes that stimulate retraction. "Honest error" is one reason. ${ }^{12}$ Nor would it be a stretch to consider the process "compromised peer review" given the apparent lack of experts in the subject matter being part of the process. ${ }^{13}$ Johnson and $\mathrm{Yu}$ have been made aware of their mistakes, opening another potential reason for retraction noted in the same study-in $38 \%$ of incidences the retraction was not required by the editors but was "issued by the authors." At this writing, the nonretracted article has 190,259 views.

One wonders, in this era in which the boundaries of the scientific academy are peppered to porousness by media and social media, whether justification for retraction might simply come through applying medicine's first concern: primum non-nocere. Given the value that researchers have confirmed in complementary therapies for people undergoing often brutal oncologic practices, failure to retract likely not only causes harm but also sustains it into perpetuity for anyone who uses the Internet. The complementary medicine in cancer care kills message is there for the clicking.

JAMA Oncology cannot recall the misinformation the article has spewed into a public hungry for assistance in making informed decisions about complementary and alternative therapies during cancer treatment. But it can begin a new era of collaboration by retracting the article-or at least making a splash of publishing the critiques and inviting dialogue with the integrative oncology community.

\section{References}

1. Wikipedia. Rose is a rose is a rose is a rose. Online document at: https://en.wikipedia.org/wiki/Rose_is_a_rose_is_ a_rose_is_a_rose, accessed August 15, 2018.

2. Johnson SB, Park HS, Gross CP, Yu JB. Complementary medicine, refusal of conventional cancer therapy, and survival among patients with curable cancers. JAMA Oncol 2018. DOI:10.1001/jamaoncol.2018.2487.

3. Bakalar N. Alternative Cancer Treatments May Be Bad for Your Health. People who used herbs, acupuncture and other complementary treatments tended to die earlier than those who didn't. New York Times. 2018. Online document at: https://www.nytimes.com/2018/07/23/well/alternative-cancertreatments-therapies-harm-health-death.html, accessed October 17, 2018.

4. Weeks J. Retraction Needed? JAMA Oncology's Bum Science Suggests People Die Faster Using Complementary Medicine. Today's Practitioner: Advancing Integrative Care. 2018. Online document at: https://todayspractitioner.com/ john-weeks/retraction-needed-jama-oncologys-bum-sciencesuggests-people-die-faster-using-complementary-medicine/ \#.W-HGyNVKiUk, September 26, 2018.

5. Johnson SB, Park HS, Gross CP, Yu JB. Use of alternative medicine for cancer and its impact on survival. $J$ Natl Cancer Inst 2018;110:121-124.

6. Horneber M, Bueschel G, Dennert G, et al. How many cancer patients use complementary and alternative medicine: A systematic review and metaanalysis. Integr Cancer Ther 2018;11:187-203. 
7. Stan DL, Wahner-Roedler D, Yost KJ, et al. Absent and discordant electronic health record documentation of complementary and alternative medicine in cancer care. J Altern Complement Med 2018;24:988-995.

8. Kumbamu A, Geller G, Leppin A, et al. Contending worldviews in the clinical encounter: An empirical study of complementary and alternative medicine deliberations in contemporary medical oncology. J Altern Complement Med 2018;24:996-1002.

9. Weeks J. Interview: SIO President Lynda Balneaves on the JAMA Oncology Paper Linking Complementary Care with Early Death. Johnweeks-integrator.com. 2018. Online document at: www.johnweeks-integrator.com/uncategorized/ interview-sio-president-lynda-balneaves-on-the-jama-oncologypaper-linking-complementary-care-with-early-death, accessed October 3, 2018.

10. Lyman GH, Greenlee H, Bohlke K, et al. Integrative therapies during and after breast cancer treatment: ASCO En- dorsement of the SIO Clinical Practice Guideline. J Am Soc Clin Oncol 2018;36:2647-2655.

11. Mao JJ. Advancing the global impact of integrative oncology. JNCI Monogr 2017;2017:1gx001.

12. Van Noorden R. The reasons for retraction. News Blog. Nature.com. Online document at: http://blogs.nature.com/ news/2011/10/the_reasons_for_retraction.html, accessed October 3, 2018.

13. Moylan E, Kowalczuk M. Why articles are retracted: A retrospective cross-sectional study of retraction notices at BioMed Central. BMJ Open 2016;6:012047.

Address correspondence to:
John Weeks
johnweeks-integrator.com
Seattle, WA 98116

E-mail: jweeks.jacm@gmail.com 